\title{
BMJ Open Prevalence and severity of burnout in Hong Kong doctors up to 20 years post- graduation: a cross-sectional study
}

\author{
Amy Pui Pui Ng (D) , ${ }^{1}$ Weng Yee Chin (D) , ${ }^{1,2}$ Eric Yuk Fai Wan (D) , ${ }^{1,3}$ Julie Chen, ${ }^{1,2}$ \\ Chak Sing Lau ${ }^{4}$
}

To cite: $\mathrm{Ng}$ APP, Chin WY, Wan EYF, et al. Prevalence and severity of burnout in Hong Kong doctors up to 20 years post-graduation: a crosssectional study. BMJ Open 2020;10:e040178. doi:10.1136/ bmjopen-2020-040178

- Prepublication history for this paper is available online. To view these files, please visit the journal online (http://dx.doi. org/10.1136/bmjopen-2020040178).

Received 07 May 2020 Revised 24 September 2020 Accepted 10 October 2020

Check for updates

(C) Author(s) (or their employer(s)) 2020. Re-use permitted under CC BY-NC. No commercial re-use. See rights and permissions. Published by BMJ.

${ }^{1}$ Department of Family Medicine and Primary Care, University of Hong Kong Li Ka Shing Faculty of Medicine, Hong Kong, China ${ }^{2}$ Institute of Medical and Health Sciences Education, University of Hong Kong, Hong Kong, China ${ }^{3}$ Department of Pharmacology and Pharmacy, University of Hong Kong, Hong Kong, China ${ }^{4}$ Department of Medicine, University of Hong Kong Li Ka Shing Faculty of Medicine, Hong Kong, China

Correspondence to

Dr Weng Yee Chin;

chinwy@hku.hk

\section{ABSTRACT}

Objective To estimate the prevalence and severity of burnout and explore the factors associated with burnout among Hong Kong medical graduates up to 20 years postgraduation.

Design Cross-sectional survey.

Setting Hong Kong.

Participants Doctors who graduated from the University of Hong Kong between 1995 and 2014.

Primary and secondary outcome measures Burnout as measured by the Copenhagen Burnout Inventory (CBI), alcohol consumption as measured by the Alcohol Use Disorders Identification Test Version C, lifestyle behaviours (hours of sleep and work, exercise, smoking, substance use), career satisfaction and sociodemographic characteristics were obtained using paper or online questionnaires.

Results Response rate was 30.9\% (496/1607) Prevalence of CBI burnout was $63.1 \%$ (personal), $55.9 \%$ (work-related) and $35.4 \%$ (patient-related). The mean CBI subscale scores were $57.4 \pm 21.4$ (personal), $48.9 \pm 7.4$ (work-related) and 41.5 \pm 21.8 (client-related). Factors associated with personal and patient-related burnout included age (coeff $-0.437,95 \% \mathrm{Cl}-0.779$ to -0.095 and coeff $-0.596,95 \% \mathrm{Cl}-0.965$ to -0.228 , respectively), practice setting (coeff $-5.759,95 \% \mathrm{Cl}-10.665$ to -0.853 and coeff $-5.317,95 \% \mathrm{Cl}-10.602$ to -0.032 , respectively) and regular exercise (coeff $-6.855,95 \% \mathrm{Cl}$ -11.102 to -2.608 and coeff $-6.769,95 \% \mathrm{Cl}-11.333$ to -2.205 , respectively). Gender (coeff $5.1,95 \% \mathrm{Cl} 1.382$ to 8.818 ), average hours of sleep per night (coeff -5.200 , $95 \% \mathrm{Cl}-7.139$ to -3.262 ) and work hours per week (coeff $0.226,95 \% \mathrm{Cl} 0.099$ to 0.353 ) were associated with personal burnout only. No factors were significantly associated with work-related burnout.

Conclusion Burnout is highly prevalent among Hong Kong medical graduates. Younger doctors, women and those working in the public sector appear to be at higher risk for burnout and may benefit from targeted interventions. Policymakers and healthcare authorities should consider measures to help reduce burnout by enabling adequate sleep, reducing work hours and encouraging exercise.

\section{INTRODUCTION}

Medicine is a high-stake, high-pressure profession with little time for self-renewal. Burnout, a measurement of physical and

\section{Strengths and limitations of this study}

- This is the first Hong Kong (HK) doctor burnout study using the Copenhagen Burnout Inventory to measure burnout.

- The response rate was $30.9 \%$, which is not unusual for many doctor studies; however, the results may be affected by substantial selection and response bias.

- This study represents only a proportion of early to mid-career HK doctors as only the graduates of one of the two medical schools in HK were sampled and foreign-trained doctors were not included.

- The survey was cross-sectional and therefore we are unable to determine if the associations are causally related.

- Further large-scale studies including later career doctors are needed to gain a more complete picture of burnout across the career span.

psychological exhaustion, has been reported to be higher in physicians than in the general population. ${ }^{1}$ Physician burnout has a number of implications at both individual and institutional levels. At the individual level, burnout is a predictor of well-being, ${ }^{2}$ selfrated health status ${ }^{3}$ and mood disorders ${ }^{4}$ in physicians. At an institutional level, burnout affects the quality of healthcare. Studies show that doctors with burnout make more mistakes, ${ }^{5}$ have reduced professional work effort, ${ }^{6}$ have poorer patient-doctor communication ${ }^{7}$ and self-report suboptimal care to patients. ${ }^{4}$ Burnout has also been associated with increased days of work absenteeism, ${ }^{8}$ increased intention to leave their work, ${ }^{9}$ earlier retirement and reduced clinic hours. ${ }^{10}$ Recently, burnout has also been correlated to physician leadership behaviours. ${ }^{11}$

The definition of burnout has evolved over time. Maslach described burnout as a prolonged response to chronic emotional and interpersonal stressors on the job across three dimensions: emotional exhaustion, depersonalisation and reduced personal 
accomplishment. Her widely used Maslach Burnout Inventory (MBI) measures these dimensions ${ }^{12}$ and has been the instrument of choice in $85.7 \%$ of physician burnout studies prior to June 2018. ${ }^{13}$ However, inconsistencies in selecting the cut-off scores used to define burnout have resulted in a wide range of burnout prevalence ranging from $0 \%$ to $80.5 \%{ }^{13}$ In addition, MBI only focuses on work-related exhaustion, without considering legitimate factors outside of work such as family responsibilities and health issues. ${ }^{14}$ A more recent definition expands on the traditional definition so that aspects not directly related to work are also measured: burnout is a condition that results from severe stress relative to one's own emotional and cognitive reserves. ${ }^{14}$ These endpoints of fatigue and exhaustion are captured in the Copenhagen Burnout Inventory (CBI) that was introduced in 2005. The CBI broadens the scope of burnout into three subscales: personal, work-related and client-related burnout. Personal burnout is 'the degree of physical and psychological fatigue and exhaustion experienced by the person'. ${ }^{15}$ Work-related burnout is 'the degree of physical and psychological fatigue and exhaustion that is perceived by the person as related to his/her work'. Client-related burnout is 'the degree of physical and psychological fatigue and exhaustion that is perceived by the person as related to his/her work with clients' ${ }^{15}$ For physicians, client refers to the patient. CBI has yielded consistent, valid and reliable results measuring burnout in a wide range of workers in the human service sector, including physicians, and across many different countries and in different languages. ${ }^{23815-19}$

Many studies have examined the factors associated with burnout measured by either the MBI or CBI in health professionals across different stages of training. Personal characteristics such as female sex, ${ }^{2918}$ younger age, ${ }^{1720} 21$ marital status, ${ }^{22}{ }^{23}$ having children, ${ }^{21}$ work demands ${ }^{921} 23$ and practice setting ${ }^{18}$ have been associated with burnout. Career satisfaction has also been related to burnout. ${ }^{21}{ }^{23}$ Lifestyle characteristics such as smoking, ${ }^{24}$ exercise, ${ }^{9}{ }^{25}$ substance use such as alcohol use $^{26}$ and sleep ${ }^{26}{ }^{27}$ have been correlated with burnout. In recognition of this problem, there has been an international trend to examine and maintain physician well-being as demonstrated by numerous dedicated support mechanisms and resources which exist in many countries. ${ }^{28} 29$

In Hong Kong (HK), there has been one study of physician burnout examining public sector doctors aged 30.5-44 years old which found the prevalence of burnout as measured by the MBI to be $31.9 \% .{ }^{20}$ However, $48.9 \%$ of HK doctors work in the private sector, ${ }^{30}$ so there is large pool of doctors, with different demographics, scope of practice and lifestyle issues that have not been studied. In addition, the more holistic CBI may be able to provide a more nuanced perspective of physician burnout. This study aims to provide data to fill these gaps by examining the prevalence and severity of burnout in HK doctors working in both the private and public sectors up to 20 years post-graduation. We also aim to explore the relationship between burnout and sociodemographics, lifestyle behaviours and career satisfaction. Investigation into this area may provide important insights which can have significant implications for physician well-being, patient care, health services and residency programme curricula.

\section{METHODS}

The target population comprised of all doctors entering medical school at the University of Hong Kong between 1995 and 2014 and who had a valid email or postal address $(\mathrm{N}=1607)$. Questionnaire administration took place between 29 January 2016 and 15 April 2016.

The sample size calculation was based on the assumption that a minimum of 10 subjects were required for regression analysis. ${ }^{31}$ However, since another study showed that there is better power to detect a small effect size with 30 participants per variable, 390 participants were needed to examine the 13 predictors in this study. ${ }^{32}$

Subjects were invited by email to complete an online survey via SoGO Survey, a third-party service often used for graduate surveys. To ensure respondents remained anonymous and to avoid duplicated responses, each participant was allocated a unique identifying number. Response rates were tracked electronically by SoGO Survey.

During the sampling period, an initial invitation email was sent followed by a reminder email every 14 days with a maximum of 3 reminders sent. As an incentive, respondents were offered a coffee coupon if they provided an email contact in the survey. Initially 384 responses were received using the online survey. In order to increase the sample size, paper questionnaires were subsequently mailed to graduates with available mailing addresses resulting in a further 112 responses. In total 496 graduates completed the survey. The subject recruitment flow chart is shown in figure 1 .

\section{Measurement instruments}

The Copenhagen Burnout Inventory

The CBI was used to measure burnout. The CBI is a 19-item questionnaire that measures exhaustion. It encompasses three types of physical and psychological exhaustion: personal, work-related and patient-related. There are six personal burnout questions related to physical and emotional fatigue, seven work-related burnout questions addressing frustration and exhaustion associated with work, and six patient-related questions developed to address symptoms of frustration and emotional exhaustion associated with a doctor's work involving patients. All items are assessed according to a 5-point Likert scale: always or to a very high degree; often or to a high degree; sometimes or somewhat; seldom or to a low degree; and never/almost never or to a very low degree ${ }^{8}$ with each of the answer assigned a certain number of points: $0,25,50$, 75 and 100, respectively. The burnout level is calculated as a mean score; therefore, every scale has a value $0-100$. A score of $\geq 50$ indicates a high degree of burnout. ${ }^{17} 1823$ In this study, the Cronbach's alpha coefficients were 0.92 , 


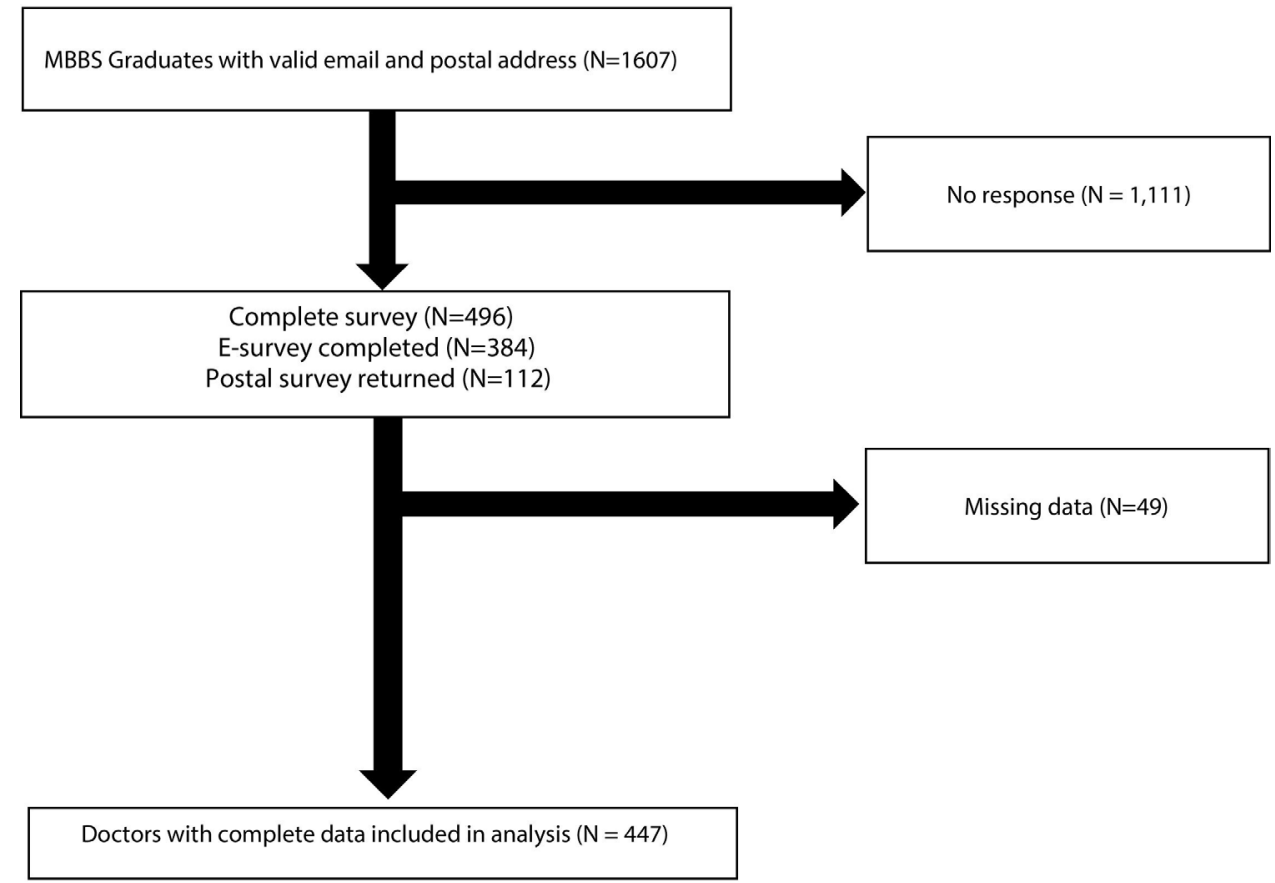

Figure 1 Flow chart showing the sampling and response rates. MBBS, Bachelor of Medicine and Bachelor of Surgery.

0.85 and 0.90 for personal, work-related and patientrelated subscales, respectively providing evidence that the CBI was a reliable measure with good subscale internal consistency.

The Alcohol Use Disorders Identification Test Version C

The Alcohol Use Disorders Identification Test Version C (AUDIT-C) is a valid, effective and simple screening tool that has three questions related to at-risk drinking and is scored out of $12 .^{33}$ At-risk drinking is defined as an AUDIT-C score $\geq 3$ in accordance to the HK guidelines. ${ }^{34}$ The higher the AUDIT-C score the more likely the consumption pattern is consistent with alcohol dependence. The scores were derived from the original questionnaire and modified to fit the scoring system of AUDIT-C.

Items on job satisfaction and lifestyle behaviours were derived and adapted from existing doctor questionnaires $^{3536}$ and the local HK population health survey. ${ }^{37}$

\section{DATA ANALYSIS}

Descriptive statistics were used to summarise the characteristics, lifestyle behaviour and career satisfaction of the respondents. The prevalence and scores of CBI personal, work-related and patient-related domains were calculated. Prevalence of burnout was calculated by determining the proportion of respondents with CBI scores $\geq 50$. Univariate linear regression was used to evaluate the effect of sociodemographic factors, lifestyle behaviours and career satisfaction. Factors that were significantly associated with the CBI were included in the multivariable linear regression models using a backward stepwise selection. Multicollinearity and residual normality assumption were examined using a variance inflation factor and QQ-plot. The models satisfied these assumptions.

All significance tests were two tailed and findings with $p$ value $<0.05$ were considered statistically significant. All statistical analyses were performed using Stata V.15.0 (StataCorp, College Station, Texas, USA).

\section{RESULTS}

A total of 496 completed surveys were received from a sample of 1607 medical graduates giving a response rate was $30.9 \%$. After excluding 49 participants with missing data, 447 subjects were included in the analysis. The subject recruitment flow chart is shown in figure 1 .

As shown in table 1 , the prevalence of burnout as measured by the CBI was $63.1 \%$ (personal burnout),

Table 1 Prevalence of the personal, work-related and patient-related Copenhagen Burnout Inventory (CBI) score

Doctors $(\mathrm{N}=447)$

\begin{tabular}{ll}
\hline CBI score & \\
Burnout-personal & $57.4 \pm 21.4$ \\
Burnout -work-related & $48.9 \pm 7.4$ \\
Burnout - patient-related & $41.5 \pm 21.8$ \\
CBI prevalence (score $(\geq 50)$ & \\
Burnout-personal & $282(63.1 \%)$ \\
Burnout-work-related & $250(55.9 \%)$ \\
Burnout-patient-related & $158(35.4 \%)$
\end{tabular}

All data are represented in mean \pm SD or total (\%), as appropriate. No data shown for missing value. 
Table 2 Descriptive statistics on sociodemographic, lifestyle behaviour and career satisfaction

\section{Doctors ( $\mathrm{N}=447)$}

Doctors $(\mathrm{N}=447)$

\begin{tabular}{llll}
\hline Sociodemographic & \multicolumn{3}{l}{ Lifestyle behaviour } \\
Age & $34.1 \pm 6.0$ & Average sleep per night & $6.6 \pm 1.0$ \\
\hline Gender (female) & $195(43.6 \%)$ & Hours of work per week & $54.7 \pm 15.1$ \\
\hline Marital status & & Regular exercise & $340(76.1 \%)$ \\
Single, separated and divorced & $201(45.0 \%)$ & At-risk drinker & $98(24.8 \%)$ \\
Married & $246(55.0 \%)$ & Current smoker & $4(0.9 \%)$ \\
Having children & $177(39.6 \%)$ & Substance use & $6(1.3 \%)$ \\
Setting of practice & & Career satisfaction & \\
Public & $346(77.4 \%)$ & Satisfied with present job position & $359(80.7 \%)$ \\
Private & $101(22.6 \%)$ & Satisfied with being a medical doctor & $418(93.7 \%)$ \\
\hline
\end{tabular}

Current smoker (current smoker vs non-smoker/ex-smoker); regular exercise (5 or more days per week for at least 10 min per day/any vigorous and moderate physical activities); private practice (private solo/private hospital/non-government organisation); public practice (university/government/hospital authority/not applicable); at-risk drinkers (>3 AUDIT-C score), AUDIT-C score was calculated by the sum of score based on the frequency of drinking alcohol, the average number of standard drinks per day and the frequency of taking five or more drinks on one occasion, ranging from 0-12. The frequency of drinking alcohol (less than once per month/once per month/two to three times per month or once per week/two to three times per week/four to six times per week or every day) was ranked 0-4, respectively; the average number of standard drinks per day (one to two drinks/three to four drinks/five to six drinks/seven to eight drinks/nine or more drinks) was ranked 0-4, respectively; the frequency of taking five or more drinks on one occasion (never/less than once per week/monthly/weekly/daily or almost daily) was ranked 0-4, respectively. All data are represented in mean \pm SD or total (\%), as appropriate. No data shown for missing value.

AUDIT-C, Alcohol Use Disorders Identification Test Version C .

$55.9 \%$ (work-related burnout) and $35.4 \%$ (patient-related burnout). The mean CBI subscale scores were 57.4 \pm 21.4 (personal), $48.9 \pm 7.4$ (work-related) and 41.5 \pm 21.8 (patient-related).

Sociodemographics, lifestyle behaviours and professional satisfaction are displayed in table 2. Mean age of the respondents was $34.1 \pm 6.0$ years (range $24-46$ years), and $43.6 \%$ were women. A majority of respondents indicated they were satisfied with their current job position $(80.7 \%)$ and with their career choice as a doctor (93.7\%).

Tables 3-5 show the results of the regression analysis identifying the factors associated with personal, workrelated and patient-related burnout. Although the age range of the participants was limited to 22 years, age was still included in the regression analysis to try to differentiate early and mid-career doctors. Being of younger age and female, working in the public sector, sleeping fewer hours per night, working longer hours per week and not having regular exercise were significantly associated with higher CBI personal scores. There were no factors shown to be related to CBI work-related scores. Being of younger age, working in the public sector and not having regular exercise were associated with higher patient-related CBI scores.

\section{DISCUSSION}

This study found that burnout was very prevalent among doctors who graduated from a local HK university. The prevalence of the CBI burnout subscales ranged between $35 \%$ and $63 \%$ with symptoms of personal burnout being the most prevalent and severe. The mean age of our respondents was 34.1 years, as we only surveyed doctors up to 20 years post-graduation. In our study, the prevalence of burnout as measured by CBI was higher than those reported in Canadian physicians in all subscales ${ }^{23}$ and, when compared with doctors in Taiwan, HK doctors had slightly lower prevalence of patient-related burnout, but higher prevalence of personal and work-related burnouts. ${ }^{17}$ In the Canadian and Taiwanese studies, however, the mean age of the participants was approximately 10 years older than our current study population. When comparing with studies conducted among younger doctors, our study respondents had a higher prevalence of CBI burnout in all subscales than Australian physicians $^{18}$ and a higher prevalence of personal and workrelated burnout, but similar patient-related burnout to Indian resident medical officers. ${ }^{38} \mathrm{~A}$ study on French emergency physicians using the MBI found that the prevalence of burnout was $50.7 \% .{ }^{39}$ On the other hand, Siu et al showed that prevalence of burnout using the MBI was $31.9 \%$ in HK doctors which is lower than all three subscales of burnout found in this study. ${ }^{20}$ Other studies have shown a similar trend of higher prevalence of personal burnout, followed by work-related then patientrelated burnout ${ }^{171823}$ in doctors. With respect to burnout severity, HK doctors' scores were in line with the global ranges for all three subscales: personal burnout scores ranging from 39 to $62,{ }^{2}{ }^{16-18} 2338$ work-related scores ranging from 33 to $58^{17182338}$ and patient-related scores ranging from 22 to $62 .{ }^{1718} 2338$

Compared with the lifestyle characteristics of the general HK population, HK doctors sleep less, ${ }^{40}$ work longer 
Table 3 Sociodemographic, lifestyle behaviour and career satisfaction associated with personal CBI score by regression analysis

\begin{tabular}{|c|c|c|c|c|c|c|}
\hline \multirow[b]{3}{*}{ Factor* } & \multicolumn{6}{|c|}{ Personal CBI score $(n=447)$} \\
\hline & \multicolumn{3}{|l|}{ Univariate } & \multicolumn{3}{|c|}{ Multivariable with backward selection } \\
\hline & Coeff. & $95 \% \mathrm{Cl}$ & $P$ value & Coeff. & $95 \% \mathrm{Cl}$ & $P$ value \\
\hline \multicolumn{7}{|l|}{ Sociodemographic } \\
\hline Age & $-0.835 \dagger$ & $(-1.159$ to 0.511$)$ & $<0.001 \dagger$ & $-0.437 \dagger$ & $(-0.779$ to 0.095$)$ & $0.012 \dagger$ \\
\hline Female (vs male) & $4.947 \dagger$ & (0.962 to 8.932$)$ & $0.015 \dagger$ & $5.100 \dagger$ & (1.382 to 8.818$)$ & $0.007 \dagger$ \\
\hline $\begin{array}{l}\text { Married (vs single, separated and } \\
\text { divorced) }\end{array}$ & $-5.734 \dagger$ & $(-9.697$ to 1.771$)$ & $0.005 \dagger$ & NA & & \\
\hline Having children & $7.124 \dagger$ & (3.111 to 11.137$)$ & $0.001 \dagger$ & & & \\
\hline Private setting of practice (vs public) & $-12.327 \dagger$ & $(-16.943$ to 7.711$)$ & $<0.001 \dagger$ & $-5.759 \dagger$ & $(-10.665$ to 0.853$)$ & $0.022 \dagger$ \\
\hline \multicolumn{7}{|l|}{ Health status } \\
\hline Average sleep per night & $-6.505+$ & $(-8.497$ to 4.514$)$ & $<0.001 \dagger$ & $-5.200 \dagger$ & (-7.139 to 3.262$)$ & $<0.001 \dagger$ \\
\hline Hours of work per week & $0.361 \dagger$ & (0.233 to 0.488$)$ & $<0.001 \dagger$ & $0.226 \dagger$ & (0.099 to 0.353$)$ & $0.001 \dagger$ \\
\hline Regular exercise & $-9.882 \dagger$ & $(-14.452$ to 5.312$)$ & $<0.001 \dagger$ & $-6.855 \dagger$ & $(-11.102$ to 2.608$)$ & $0.002 \dagger$ \\
\hline Current smoker & 5.117 & $(-16.002$ to 26.235$)$ & 0.634 & NA & & \\
\hline At-risk drinker & -1.611 & $(-6.454$ to 3.232$)$ & 0.514 & & & \\
\hline Substance use & -16.402 & $(-33.621$ to 0.817$)$ & 0.062 & & & \\
\hline \multicolumn{7}{|l|}{ Career satisfaction } \\
\hline Satisfied with present job position & -0.35 & $(-5.408$ to 4.708$)$ & 0.892 & NA & & \\
\hline Satisfied with being a medical doctor & 2.197 & $(-6.015$ to 10.409$)$ & 0.599 & & & \\
\hline
\end{tabular}

Current smoker (current smoker vs non-smoker/ex-smoker); regular exercise ( 5 or more days per week for at least 10 min per day/any vigorous and moderate physical activities); private practice (private solo/private hospital/non-government organisation); public practice (university/government/hospital authority/not applicable); at-risk drinkers ( $\geq 3$ AUDIT-C score), the AUDIT-C score was calculated by the sum of score based on the frequency of drinking alcohol, the average number of standard drinks per day and the frequency of taking five or more drinks on one occasion, ranging from 0-12. The frequency of drinking alcohol (less than once per month/once per month/two to three times per month or once per week/two to three times per week/four to six times per week or every day) was ranked 0-4, respectively; the average number of standard drinks per day (one to two drinks/three to four drinks/five to six drinks/seven to eight drinks/nine or more drinks) was ranked 0-4, respectively; the frequency of taking five or more drinks on one occasion (never/less than once per week/monthly/weekly/daily or almost daily) was ranked $0-4$, respectively.

*Variable in brackets is the reference category for independent variables. No data shown for missing value. †Significant with $\mathrm{p}$ value $<0.05$.

AUDIT-C, Alcohol Use Disorders Identification Test Version C ; CBI, Copenhagen Burnout Inventory; Coeff., coefficient; NA, not applicable.

hours, ${ }^{41}$ smoke less, ${ }^{42}$ but do more exercise. ${ }^{43}$ Adequate sleep duration and quality of sleep are important factors to reduce stress and fatigue. In this study, less sleep was associated with higher personal burnout scores only. A study of Taiwanese nurses showed that lack of sleep was associated with higher burnout in all three subscales of the CBI. ${ }^{27}$ A study of HK and Macau university students showed that quality and duration of sleep can affect physical and psychological health, such as mood. ${ }^{44}$ It can be postulated that lack of sleep can lead to poor mood which can then lead to physical and emotional exhaustion, or that lack of sleep can directly lead to physical and emotional exhaustion. Both can contribute to personal burnout. Consistent with this, doctors with longer working hours had higher CBI personal scores in this study. Longer work hours typically means there is less time to spend with family and enjoy one's personal life leading to higher personal burnout. ${ }^{39}$ Studies have shown that longer work hours translate to more work-family conflicts and there is a positive dose-response relationship between workfamily conflict and personal burnout. ${ }^{9}$ In a Taiwanese study of first year postgraduate doctors, all three dimensions of the CBI were related to work hours. ${ }^{45}$ However, measuring work demands is complicated. Siu et al s HK doctor burnout study did not show that working hours was associated with higher MBI burnout scores, but working in shifts was. ${ }^{20}$ Number of nights on call per week, ${ }^{21}$ quantitative workload ${ }^{23}$ working overtime, ${ }^{17}$ working in shifts ${ }^{17}$ and inadequate time off work ${ }^{3}$ have also been shown to contribute to more burnout.

Similar to Siu et al's HK study, we found that smoking and substance abuse was low among the samples and did not show any correlation with burnout. ${ }^{20}$ Although $24.8 \%$ of the respondents in our sample fell into the 'at-risk' category for alcohol use, this level of drinking was not correlated with burnout which was also similar to Siu et $a l$ s HK study and a Taiwan study on doctors. ${ }^{46}$ In contrast, studies on US physicians have shown that alcohol abuse 
Table 4 Sociodemographic, lifestyle behaviour and career satisfaction associated with work-related CBI score by regression analysis

Work-related CBI score $(n=447)$

\begin{tabular}{|c|c|c|c|c|c|c|}
\hline \multirow[b]{2}{*}{ Factor* } & \multicolumn{3}{|c|}{ Univariate } & \multicolumn{3}{|c|}{$\begin{array}{l}\text { Multivariable with } \\
\text { backward selection }\end{array}$} \\
\hline & Coeff. & $95 \% \mathrm{Cl}$ & $P$ value & Coeff. & $95 \% \mathrm{Cl}$ & $P$ value \\
\hline \multicolumn{7}{|l|}{ Sociodemographic } \\
\hline Age & 0.105 & $(-0.009$ to 0.219$)$ & 0.072 & NA & & \\
\hline Female (vs male) & 0.142 & $(-1.240$ to 1.524$)$ & 0.84 & & & \\
\hline Married (vs single, separated and divorced) & 1.213 & $(-0.161$ to 2.586$)$ & 0.083 & & & \\
\hline Having children & -0.991 & $(-2.390$ to 0.408$)$ & 0.165 & & & \\
\hline Private setting of practice (vs public) & -1.079 & $(-2.715$ to 0.557$)$ & 0.196 & & & \\
\hline \multicolumn{7}{|l|}{ Health status } \\
\hline Average sleep per night & -0.29 & $(-1.010$ to 0.430$)$ & 0.429 & NA & & \\
\hline Hours of work per week & 0.041 & $(-0.004$ to 0.086$)$ & 0.076 & & & \\
\hline Regular exercise & -0.62 & $(-2.225$ to 0.986$)$ & 0.449 & & & \\
\hline Current smoker & -4.562 & $(-11.829$ to 2.705$)$ & 0.218 & & & \\
\hline At-risk drinker & 0.402 & $(-1.270$ to 2.074$)$ & 0.637 & & & \\
\hline Substance use & 0.058 & $(-5.899$ to 6.015$)$ & 0.985 & & & \\
\hline \multicolumn{7}{|l|}{ Career satisfaction } \\
\hline Satisfied with present job position & -0.538 & $(-2.279$ to 1.203$)$ & 0.544 & NA & & \\
\hline Satisfied with being a medical doctor & 0.676 & $(-2.154$ to 3.506$)$ & 0.639 & & & \\
\hline
\end{tabular}

Current smoker (current smoker vs non-smoker/ex-smoker); regular exercise ( 5 or more days per week for at least 10 min per day/any vigorous and moderate physical activities); private practice (private solo/private hospital/non-government organisation); public practice (university/government/hospital authority/not applicable); at-risk drinkers ( $\geq 3$ AUDIT-C score), the AUDIT-C score was calculated by the sum of score based on the frequency of drinking alcohol, the average number of standard drinks per day and the frequency of taking five or more drinks on one occasion, ranging from 0-12. The frequency of drinking alcohol (less than once per month/once per month/two to three times per month or once per week/two to three times per week/four to six times per week or every day) was ranked 0-4, respectively; the average number of standard drinks per day (one to two drinks/three to four drinks/five to six drinks/seven to eight drinks/nine or more drinks) was ranked 0-4, respectively; the frequency of taking five or more drinks on one occasion (never/less than once per week/monthly/weekly/ daily or almost daily) was ranked $0-4$, respectively.

*Variable in brackets is the reference category for independent variables. No data shown for missing value.

AUDIT-C, Alcohol Use Disorders Identification Test Version C ; CBI, Copenhagen Burnout Inventory; Coeff., coefficient; NA, not applicable.

and dependence can be related to burnout. ${ }^{26}$ These findings may suggest that HK physicians are less likely to turn to alcohol as a coping mechanism for stress. Nurses working in HK cope with stress by seeking support from friends and colleagues, using different cognitive strategies and through leisure activities, ${ }^{47}$ and the most common method of stress relief in the general HK population is exercise ${ }^{42}$ This is likely similar in HK physicians. It is reassuring that most doctors perform regular exercise in HK, and exercise was found to be protective for personal and patient-related burnout. Siu et al s study did not find that exercise was a stress-relieving factor against burnout. ${ }^{20}$ However, the positive effects of exercise on burnout have been seen in some studies in Taiwan, ${ }^{46}$ France $^{9}$ and the $\mathrm{USA}^{48}{ }^{48}$ similar to the findings of this study.

The relationship between sociodemographic characteristics and burnout shows that age, sex and doctor's practice setting is associated with burnout in HK physicians. Previous studies examining doctors' age and burnout scores have been inconsistent. A study on young
Australasian fellows did not show significant relationships of the three dimensions of CBI with age ${ }^{18}$; but another study of medical professionals in Taiwan found that older doctors had significantly lower burnout scores than younger doctors on all three dimensions of the CBI. The mean age of the physicians in the Taiwanese study was 11 years older than the mean age of the present study. ${ }^{17}$ Our study found that only personal burnout and patientrelated burnout were associated with age. Although the age range of the doctors in this study was small (ranging from 24 to 46 years), it is wide enough to a contrast between the doctors in their early and mid-careers. This is supported by at least one study showing that residents tend to have higher burnout scores compared with attending physicians. ${ }^{49}$ The younger cohorts are at a life stage where they may be looking for a spouse, getting married and having children. However, at the same time, they also need to complete their postgraduate training and develop their career paths. This tension between personal and professional responsibilities has been termed 'work-home 
Table 5 Sociodemographic, lifestyle behaviour and career satisfaction associated with patient-related CBI score by regression analysis

Patient-related CBI score $(n=447)$

Univariate

Multivariable with backward selection

\begin{tabular}{|c|c|c|c|c|c|c|}
\hline Factor* & Coeff. & $95 \% \mathrm{Cl}$ & $P$ value & Coeff. & $95 \% \mathrm{Cl}$ & $P$ value \\
\hline \multicolumn{7}{|l|}{ Sociodemographic } \\
\hline Age & $-0.755 \dagger$ & $(-1.088$ to 0.423$)$ & $<0.001 \dagger$ & $-0.596 \dagger$ & $(-0.965$ to 0.228$)$ & $0.002 \dagger$ \\
\hline Female (vs male) & 0.418 & $(-3.673$ to 4.509$)$ & 0.841 & NA & & \\
\hline $\begin{array}{l}\text { Married (vs single, separated and } \\
\text { divorced) }\end{array}$ & -3.807 & $(-7.870$ to 0.256$)$ & 0.066 & & & \\
\hline Having children & $6.271 \dagger$ & (2.164 to 10.378$)$ & $0.003 \dagger$ & & & \\
\hline Private setting of practice (vs public) & $-8.999 \dagger$ & $(-13.777$ to 4.221$)$ & $<0.001 \dagger$ & $-5.317 \dagger$ & $(-10.602$ to 0.032$)$ & $0.049 \dagger$ \\
\hline \multicolumn{7}{|l|}{ Health status } \\
\hline Average sleep per night & $-2.540 \dagger$ & (-4.642 to 0.438$)$ & $0.018 \dagger$ & NA & & \\
\hline Hours of work per week & 0.119 & $(-0.015$ to 0.253$)$ & 0.082 & & & \\
\hline Regular exercise & $-6.932 \dagger$ & $(-11.643$ to 2.222$)$ & $0.004 \dagger$ & $-6.769 \dagger$ & $(-11.333$ to 2.205$)$ & $0.004 \dagger$ \\
\hline Current smoker & -2.98 & (-24.521 to 18.561$)$ & 0.786 & & & \\
\hline At-risk drinker & -1.296 & (-6.224 to 3.633$)$ & 0.606 & NA & & \\
\hline Substance use & -5.101 & $(-22.724$ to 12.522$)$ & 0.57 & & & \\
\hline \multicolumn{7}{|l|}{ Career satisfaction } \\
\hline Satisfied with present job position & -0.022 & $(-5.170$ to 5.125$)$ & 0.993 & NA & & \\
\hline Satisfied with being a medical doctor & -1.125 & $(-9.490$ to 7.240$)$ & 0.792 & & & \\
\hline
\end{tabular}

Current smoker (current smoker vs non-smoker/ex-smoker); regular exercise (5 or more days per week for at least 10 min per day/any vigorous and moderate physical activities); private practice (private solo/private hospital/non-government organisation); public practice (university/government/hospital authority/not applicable); at-risk drinkers ( $>3$ AUDIT-C score), the AUDIT-C score was calculated by the sum of score based on the frequency of drinking alcohol, the average number of standard drinks per day and the frequency of taking five or more drinks on one occasion, ranging from 0-12. The frequency of drinking alcohol (less than once per month/once per month/two to three times per month or once per week/two to three times per week/four to six times per week or every day) was ranked 0-4, respectively; the average number of standard drinks per day (one to two drinks/three to four drinks/five to six drinks/seven to eight drinks/nine or more drinks) was ranked 0-4, respectively; the frequency of taking five or more drinks on one occasion (never/less than once per week/monthly/weekly/daily or almost daily) was ranked $0-4$, respectively.

*Variable in brackets is the reference category for independent variables. No data shown for missing value.

†Significant with $\mathrm{p}$ value $<0.05$.

AUDIT-C, Alcohol Use Disorders Identification Test Version C ; CBI, Copenhagen Burnout Inventory; Coeff., coefficient; NA, not applicable.

interference' and studies have shown that this has an effect on personal burnout. ${ }^{50}$ Younger physicians who are just starting out may have a steep learning curve when it comes to patient interactions. Although they have exposure to patients during medical school, students have a supervising physician to fill in the deficient areas. When the student graduates and becomes a doctor, they take on more responsibility and are required to perform tasks they may not be confident in performing, which may contribute to increased patient-related burnout in their early career. A study of HK dentists found that patientrelated stressors such as actually and possibly making mistakes, having a medical emergency, coping with difficult patients and dealing with high patient expectations were among their top ranked stressors. ${ }^{51}$ One can argue that these patient-related factors would also be relevant to younger, less experienced medical doctors contributing to higher patient-related burnout scores. The relationship between age and work-related burnout may depend on additional factors such as level of experience. Siu $e t a l$ s study of HK doctors found that young but moderately experienced doctors were most at risk for burnout. ${ }^{20} \mathrm{~A}$ possible reason for this is that new doctors may not have as much work responsibility at the beginning. However, as experience increases so does responsibility and the corresponding increase in stress.

Consistent with our findings, many studies using CBI have shown that female physicians are more at risk for personal burnout. $^{2} 391852$ A French study showed that work-family conflict was the greatest risk factor for high personal burnout in female doctors. ${ }^{9}$ Single female doctors have difficulty finding spouses which can be related to not having enough time to find a partner or other social barriers. ${ }^{53}$ Married female doctors have more domestic duties and child-rearing responsibilities than men. ${ }^{353}$ Furthermore, gender roles remain strictly 
defined in China where the husband bears the breadwinner role and the wife assumes the home maker role which adds to the disconnect between work and home, contributing to higher personal burnout among women doctors. ${ }^{54}$

We found that public sector doctors in our study had significantly higher CBI personal and patient-related burnout scores. There were $46.9 \%$ of doctors working in the public sector and $48.9 \%$ of HK doctors working in the private sector in $2015,{ }^{30}$ but there were almost 4.5 times more inpatient discharges in the public compared with the private sector. ${ }^{55}$ This describes a much larger patient load in the public sector, which can lead to longer work hours and increased workload. This invariably leads to more exhaustion during their non-working hours and while seeing patients. In addition, burnout has been shown to double the risk of intent to leave the profession. ${ }^{9}$ It is conceivable that the increasing attrition rate in the public sector may be a reflection of the high burnout, which grew from $4.4 \%$ to $5.9 \%$ per year during $2015-$ $2018 .^{56}$ Burnt out HK physicians may desire to leave the public sector and join the private sector or leave practice altogether. The results of a survey in 2014 of emergency physicians in HK found that $65 \%$ considered leaving the public accident and emergency department, with unhealthy working environment and enormous work load cited as being the main reasons. ${ }^{57}$

Although 55.9\% of participants had work-related burnout, it was not correlated to any of the sociodemographic factors, lifestyle behaviours and career satisfaction items. HK is known for its hard-working culture where many professions in the city also experience long hours and stress. A survey in 2008 conducted on HK employees showed the average working week was 49.6 hours: $62.4 \%$ regularly worked unpaid overtime and $51.7 \%$ worked late into the evenings with $80 \%$ reporting that the reason that they work late was because they have too much work. ${ }^{41}$ It is possible that working professionals in HK have normalised a fast pace, high-pressure working environment and therefore, may not perceive workrelated burnout like in other countries, hence cultural and contextual factors contributing to the perception of work-related burnout in HK doctors may differ.

Finally, it is important to note that despite the high prevalence and severity of burnout, burnout was not correlated with career satisfaction in the current study, with the majority of respondents reporting good satisfaction with their present job position and in their choice of being a doctor.

\section{LIMITATIONS}

Our study has several limitations. First, response rate was only $30.9 \%$, which could introduce a substantial response bias: physicians who suffer burnout may be more likely to have interest in this topic and more likely to fill the survey; but, on the other hand, they may be more apathetic and less inclined to complete the survey. Second, the age range of the respondents was only 22 years and therefore does not represent HK doctors in all age groups especially those over 46 years. However, there was sufficient sampling from the spread of ages across the spectrum studied to make meaningful comparisons. Third, as there are two medical schools and foreign-trained doctors working in HK who account for $8.5 \%$ of the practising doctors in $\mathrm{HK}^{56}$ this study cannot represent the entire HK doctor population. We chose to sample from one medical school as graduates from this medical school represented approximately half the local graduates, ${ }^{58}$ and for practical reasons as we had access to their contact details. Although $48.9 \%$ of doctors work in the private sector, we only sampled $23 \%$ of private doctors. ${ }^{30}$ This is likely a reflection that recent graduates are still in training which is done in the public sector in HK. The survey was cross-sectional and we are unable to determine if the associations are causally related. Lastly, many studies do not use the same burnout inventory therefore direct comparisons cannot be made between different studies.

\section{FUTURE DIRECTION}

The results from this study indicates there is a need to further understand burnout in HK doctors. Studies have shown that burnout can lead to reduced work effort ${ }^{6}$ and has direct effects on patient care. ${ }^{59}$ Across the world, medical communities are becoming more aware of the importance of physician well-being. At the core of the Charter on Physician Well-being is the notion that well physicians can take care of their patients better. ${ }^{28}$ As such, the goal is for governing bodies, policymakers, medical organisations and individual physicians to share the responsibility to improve physician well-being. Starting from medical school, medical students should be supported in learning self-awareness of their own emotional states and needs. Recent recommendations for US graduate medical education sought to improve policies to improve trainee support for those who have children ${ }^{60}$ which is important as work-home interference is seen as an important predictor of burnout. ${ }^{61}$ Other interventions, such as introduction of a stress management course in hospitals has shown to reduce malpractice claims and medication errors compared with hospitals without such courses. ${ }^{62}$

Acknowledgements The authors thank all the participants from the Bau Institute of Medical and Health Sciences Education, Li Ka Shing Faculty of Medicine, The University of Hong Kong and the Hong Kong Academy of Medicine for their support in this study. We would also like to thank Karina Chan for assisting in project coordination, data collection, and preliminary data analysis and reporting; Nico Cheung for assisting with statistical analysis and Nicolette Ray for proofreading the final manuscript.

Contributors All authors participated in the interpretation of data, writing and critically reviewing the paper, and approved the final submitted manuscript. APPN performed the literature review, contributed to the interpretation of the results and drafted the final manuscript. JC and CSL conceptualised the study and JC drafted the initial study protocol. WYC was responsible for drafting the study protocol, obtaining the grant, supervising the data collection, supervising the writing of the manuscript and proofreading the final manuscript. EYFW conducted the statistical 
analyses, contributed to the interpretation of results and contributed to the final manuscript.

Funding This work was financially supported by The University of Hong Kong's Small Project Fund grant number 104003643.058678.22500.301.01. It was also supported by the Bau Institute of Medical and Health Sciences Education, Li Ka Shing Faculty of Medicine and The University of Hong Kong who provided research assistance.

Competing interests None declared.

Patient and public involvement Patients and/or the public were not involved in the design, or conduct, or reporting, or dissemination plans of this research.

Patient consent for publication Not required.

Ethics approval This study received approval from the Institutional Review Board of the University of Hong Kong/Hospital Authority Hong Kong West Cluster (UW 15-405).

Provenance and peer review Not commissioned; externally peer reviewed.

Data availability statement Data are available upon reasonable request. Anonymised data are available through request to the corresponding authors.

Open access This is an open access article distributed in accordance with the Creative Commons Attribution Non Commercial (CC BY-NC 4.0) license, which permits others to distribute, remix, adapt, build upon this work non-commercially, and license their derivative works on different terms, provided the original work is properly cited, appropriate credit is given, any changes made indicated, and the use is non-commercial. See: http://creativecommons.org/licenses/by-nc/4.0/.

\section{ORCID iDs}

Amy Pui Pui Ng http://orcid.org/0000-0003-3867-6447

Weng Yee Chin http://orcid.org/0000-0003-3171-6792

Eric Yuk Fai Wan http://orcid.org/0000-0002-6275-1147

\section{REFERENCES}

1 Shanafelt TD, Boone S, Tan L, et al. Burnout and satisfaction with work-life balance among US physicians relative to the general US population. Arch Intern Med 2012;172:1377-85.

2 Kassam A, Horton J, Shoimer I, et al. Predictors of well-being in resident physicians: a descriptive and psychometric study. J Grad Med Educ 2015;7:70-4.

3 Chambers CNL, Frampton CMA, Barclay M, et al. Burnout prevalence in New Zealand's public hospital senior medical workforce: a cross-sectional mixed methods study. BMJ Open 2016;6:e013947.

4 Lu D, Dresden S, McCloskey C, et al. Impact of burnout on selfreported patient care among emergency physicians. West J Emerg Med 2015;16:996-1001.

5 Shanafelt TD, Balch CM, Bechamps G, et al. Burnout and medical errors among American surgeons. Ann Surg 2010;251:995-1000.

6 Shanafelt TDet al. Longitudinal study evaluating the association between physician burnout and changes in professional work effort. in Mayo clinic proceedings. Elsevier, 2016.

7 Chung S, Dillon EC, Meehan AE, et al. The relationship between primary care physician burnout and patient-reported care experiences: a cross-sectional study. J Gen Intern Med 2020;35:2357-64.

8 Borritz M, Rugulies R, Bjorner JB, et al. Burnout among employees in human service work: design and baseline findings of the PUMA study. Scand J Public Health 2006;34:49-58.

9 Estryn-Behar M, Doppia M-A, Guetarni K, et al. Emergency physicians accumulate more stress factors than other physicians-results from the French SESMAT study. Emerg Med J 2011;28:397-410.

10 Dewa CS, Jacobs P, Thanh NX, et al. An estimate of the cost of burnout on early retirement and reduction in clinical hours of practicing physicians in Canada. BMC Health Serv Res 2014;14:254

11 Shanafelt TD, Makowski MS, Wang H, et al. Association of burnout, professional fulfillment, and self-care practices of physician leaders with their independently Rated leadership effectiveness. JAMA Netw Open 2020;3:e207961

12 Maslach C, Jackson SE, Leiter MP, et al. Maslach burnout inventory. Vol. 21. Palo Alto, CA: Consulting psychologists press, 1986.

13 Rotenstein LS, Torre M, Ramos MA, et al. Prevalence of burnout among physicians: a systematic review. JAMA 2018;320:1131.

14 Lall MD, Gaeta TJ, Chung AS, et al. Assessment of physician wellbeing, part one: burnout and other negative states. West $J$ Emerg Med 2019;20:278-90.
15 Kristensen TS, Borritz M, Villadsen E, et al. The Copenhagen burnout inventory: a new tool for the assessment of burnout. Work Stress 2005;19:192-207.10.1080/02678370500297720

16 Ilić IM, Arandjelović Mirjana Ž, Jovanović JM, et al. Relationships of work-related psychosocial risks, stress, individual factors and burnout - Questionnaire survey among emergency physicians and nurses. Med Pr 2017;68:167-78.

17 Chou L-P, Li C-Y, Hu SC. Job stress and burnout in hospital employees: comparisons of different medical professions in a regional hospital in Taiwan. BMJ Open 2014;4:e004185.

18 Benson S, Sammour T, Neuhaus SJ, et al. Burnout in Australasian younger fellows. ANZ J Surg 2009;79:590-7.

19 Thrush CRet al. Psychometric properties of the copenhagen burnout inventory in an academic healthcare institution sample in the U.S. Evaluation \& the health professions, 2020.

20 Siu CFY, Yuen SK, Cheung A. Burnout among public doctors in Hong Kong: cross-sectional survey. Hong Kong Med J 2012;18:186-92.

21 Shanafelt TD, Balch CM, Bechamps GJ, et al. Burnout and career satisfaction among American surgeons. Ann Surg 2009;250:463-71.

22 Al-Shoraian GMJ, Hussain N, Alajmi MF, et al. Burnout among family and general practitioners. Alexandria J Med 2011;47:359-64.10.1016/j.ajme.2011.10.005

23 Wright JG, Khetani N, Stephens D. Burnout among faculty physicians in an academic health science centre. Paediatr Child Health 2011;16:409-13.

24 Cecil J, McHale C, Hart J, et al. Behaviour and burnout in medical students. Med Educ Online 2014;19:25209.

25 Wolf MR, Rosenstock JB. Inadequate sleep and exercise associated with burnout and depression among medical students. Acad Psychiatry 2017;41:174-9.

26 Oreskovich MR, Shanafelt T, Dyrbye LN, et al. The prevalence of substance use disorders in American physicians. Am J Addict 2015;24:30-8.

27 Chin W, Guo YL, Hung Y-J, et al. Short sleep duration is dosedependently related to job strain and burnout in nurses: a cross sectional survey. Int J Nurs Stud 2015;52:297-306.

28 Thomas LR, Ripp JA, West CP. Charter on physician well-being. JAMA 2018;319:1541-2.

29 Myers MF. The well-being of physician relationships. West $J$ Med 2001:174:30-3

30 Health Do. Health manpower survey on doctors. 2015, 2015.

31 Green SB. How many subjects does it take to do a regression analysis. Multivariate Behav Res 1991;26:499-510.10.1207/ s15327906mbr2603_7

32 VanVoorhis CW, Morgan B. Understanding power and rules of thumb for determining sample sizes. J Tutorials in quantitative methods for psychology 2007;3:3-50.

33 Bush K, Kivlahan DR, McDonell MB, et al. The AUDIT alcohol consumption questions (AUDIT-C) an effective brief screening test for problem drinking. Arch Intern Med 1998;158:1789-95.

34 Central Health Protection. Alcohol and health questionnaire (audit), 2017. Available: https://www.chp.gov.hk/files/pdf/dh_audit_2017_ audit questionnaire en.pdf

35 Heponiemi T, Kouvonen A, Vänskä J, et al. Health, psychosocial factors and retirement intentions among Finnish physicians. Occup Med 2008;58:406-12.

36 Taylor K, Lambert T, Goldacre M. Future career plans of a cohort of senior doctors working in the National health service. J R Soc Med 2008;101:182-90.

37 Department of Health, Central Health Protection. Report on population health survey 2003/2004.

38 Ratnakaran B, Prabhakaran A, Karunakaran V. Prevalence of burnout and its correlates among residents in a tertiary medical center in Kerala, India: a cross-sectional study. J Postgrad Med 2016;62:157-61

39 Moukarzel A, Michelet P, Durand A-C, et al. Burnout syndrome among emergency department staff: prevalence and associated factors. Biomed Res Int 2019;2019:1-10.

40 Public Opinion Programme, University of Honk Kong. Survey on the seep quality and quantity of Hong Kong's working population, 2003. Available: https://www.hkupop.hku.hk/english/archive/report/ qsleep03/release.html

41 Welford R. Work life balance in Hong Kong: survey results. Hong Kong: the University of Hong Kong and Csr Asia, 2008.

42 Centre for Health Protection, Department of Health. The government of the Hong Kong speical adminstrative region statistics on behavoural risk factors. 2008-2016. Available: https://www.chp.gov. hk/en/static/24016.htm

43 The Chinese University of Hong Kong. Survey findings on attitudes towards physical exercises in Hong Kong, 2016. 
44 Wong ML, Lau EYY, Wan JHY, et al. The interplay between sleep and mood in predicting academic functioning, physical health and psychological health: a longitudinal study. J Psychosom Res 2013;74:271-7.

45 Lue B-H, Chen H-J, Wang C-W, et al. Stress, personal characteristics and burnout among first postgraduate year residents: a nationwide study in Taiwan. Med Teach 2010;32:400-7.

46 Lin Y-L, Chen C-H, Chu W-M, et al. Modifiable risk factors related to burnout levels in the medical workplace in Taiwan: cross-sectional study. BMJ Open 2019;9:e032779.

47 Callaghan P, Tak-Ying SA, Wyatt PA. Factors related to stress and coping among Chinese nurses in Hong Kong. $J$ Adv Nurs 2000;31:1518-27.

48 Dyrbye LN, Satele D, Shanafelt TD. Healthy exercise habits are associated with lower risk of burnout and higher quality of life among U.S. medical students. Acad Med 2017;92:1006-11.

49 Wolfshohl JA, Bradley K, Bell C, et al. Association between empathy and burnout among emergency medicine physicians. J Clin Med Res 2019;11:532-8

50 Shanafelt TD, Sloan JA, Habermann TM. The well-being of physicians. Am J Med 2003;114:513-9.

51 Choy HB, Wong MC. Occupational stress and burnout among Hong Kong dentists. Hong Kong Med J 2017;23:480-8.

52 Parr JM, Pinto N, Hanson M, et al. Medical graduates, tertiary hospitals, and burnout: a longitudinal cohort study. Ochsner $J$ 2016;16:22-6.
53 Gautam M. Women in medicine: stresses and solutions. West J Med 2001;174:37-41.

54 Qian Y, Qian Z. Work, family, and gendered happiness among married people in urban China. Soc Indic Res 2015;121:61-74.

55 Goverment of Honk Kong. Hong Kong the facts public health, 2016.

56 Hong Kong Foundation. Health system capacity constraints the severe shortage of doctors in Hong Kong public hospitals, 2019.

57 Siu A. Brain drain of emergency physician in Hong Kong. J Emerg Med 2012;19:303-4.

58 Food and Health Bureau. Report of the strategic review on healthcare manpower planning and professional development; Chapter 1 - Hong Kong healthcare system and healthcare professionals. Available: https://www.fhb.gov.hk/download/press_and_publications/otherinfo/ 180500_sr/e_ch1.pdf

59 Firth-Cozens J. Doctors, their wellbeing, and their stress. BMJ 2003;326:670-1.

60 Weinstein DF, Mangurian C, Jagsi R. Parenting during graduate medical training - practical policy solutions to promote change. $N$ Engl J Med 2019;381:995-7.

61 Guille C, Zhao Z, Krystal J, et al. Web-based cognitive behavioral therapy intervention for the prevention of suicidal ideation in medical interns: a randomized clinical trial. JAMA Psychiatry 2015;72:1192-8.

62 Jones JW, Barge BN, Steffy BD, et al. Stress and medical malpractice: organizational risk assessment and intervention. J App/ Psychol 1988;4:727-35. 